PR-29

\title{
TOXIC EFFECTS OF GLYPHOSATE ON ENVIRONMENT AND HUMAN HEALTH
}

\author{
B. Gangadhar, ${ }^{1 *}$ G. Ramakrishna Naidu, ${ }^{1}$ N. Bakthavatchala Reddy ${ }^{2}$ \\ ${ }^{1}$ Department of Environmental Sciences, Sri Venkateswara University, \\ Tirupati-517 502, Andhra Pradesh, India. \\ ${ }^{2}$ Ural Federal University, Chemical Engineering Institute Yekaterinburg, \\ 620002, Russian Fedaration. \\ *Corresponding author, E-mail: gangadhar.battala@gmail.com
}

\begin{abstract}
Globally, massive amounts of pesticides are manufactured and used both in agriculture and households to get rid from various pests, some of which reach soils and aquatic systems through various pathways. Glyphosate-based herbicides $(\mathrm{GlyBH})$, including Roundup, are the most widely used pesticides worldwide. Glyphosate is a non-selective herbicide that is effective against all types of weeds and has been used for many years. Their uses have increased exponentially since their introduction into the market. Residue levels in food or water, as well as human exposures, are escalating including in the environmental segments. It can therefore be found as a contaminant in water, and procedures are required for its removal. This work investigates the toxic effects associated with the use of Glyphosate on environmental and human health.
\end{abstract}

